\title{
Retraction Note to: Reward anticipation enhances brain activation during response inhibition
}

Patricia Rosell-Negre $^{1} \cdot J_{u a n}$ Carlos Bustamante ${ }^{1} \cdot$ Paola Fuentes-Claramonte ${ }^{1}$. Víctor Costumero $^{1} \cdot$ Sergio Benabarre ${ }^{2}$ - Alfonso Barros-Loscertales ${ }^{1}$

\section{Retraction to: Cogn Affect Behav Neurosci}

\section{DOI 10.3758/s13415-014-0292-9}

At the request of the authors, this paper is retracted because the fMRI data were modeled incorrectly such that all analyses involving interaction and correlational effects in Table 2 are not valid. The Editor-in-Chief approves this retraction.

The online version of the original article can be found at http://dx.doi. org/10.3758/s13415-014-0292-9.

Alfonso Barros-Loscertales barros@uji.es

1 Departamento de Psicología Básica, Clínica y Psicobiología, Universitat Jaume I, Castelló de la Plana, Spain

2 Unidad Docente Medicina Familiar y Comunitaria, Instituto Aragonés de Ciencias de la Salud (IACS), Zaragoza, Spain 